\title{
Correction to: Piriformis pyomyositis, a cause of piriformis syndrome-a systematic search and review
}

\author{
Md Abu Bakar Siddiq ${ }^{1,2}$ (D) Johannes Jacobus Rasker ${ }^{3}$
}

Published online: 28 May 2019

(C) International League of Associations for Rheumatology (ILAR) 2019

\section{Correction to: Clinical Rheumatology https://doi.org/10.1007/s10067-019-04552-y}

The First name of the co-author of the article mentioned above was incomplete. The author's complete name should have been "Md Abu Bakar Siddiq" instead of "Abu Bakar Siddiq". The original article has been corrected.

Publisher's note Springer Nature remains neutral with regard to jurisdictional claims in published maps and institutional affiliations.

The online version of the original article can be found at https://doi.org/ 10.1007/s10067-019-04552-y

$\triangle$ Md Abu Bakar Siddiq

abusiddiq37@yahoo.com

Johannes Jacobus Rasker

j.j.rasker@utwente.nl

1 Department of Physical Medicine and Rheumatology, Brahmanbaria Medical College, Brahmanbaria, Bangladesh

2 Department of Rheumatology, University of South Wales,

Newport, UK

3 Department of Rheumatology, Faculty of Behavioral Science,

University of Twente, Enschede, Netherlands 